Egyptian

Orthodontic Journal

\title{
Comparative Study of Root Resorption between two Methods for Accelerated Orthodontic Tooth Movement
}

\author{
Ahmed Ragab Elkalza ${ }^{1}$, Ahmed Shawkat Rateb ${ }^{2}$
}

\section{ABSTRACT:}

Objective: The aim of this study was to assess apical root resorption (RR) following the application of micro-osteoperforation (MOP) and piezocision (PzC) assisted orthodontics for acceleration of tooth movement (TMM). Materials and Methods: $\mathcal{A}$ total number of 16 patients seeking orthodontic therapy were included in this study. All patients undergone $1^{\text {st }}$ premolars extraction and were indicated for canine retraction afterwards. These patients were divided into 2 groups; group $\mathcal{A}$ was treated using MOP in one side and the other side serves as control. While in group $\mathscr{B} P z C$ was performed in one side and no intervention was done to the other side. CBCT scans were taken for every patient before and after canine retraction in order to evaluate amount of $\mathbb{R} R$ in 6oth groups. Results: In MOP group, there was no significant difference in canine root length between experimental and control sides. Whereas, in PzC group, there was statistically significant decrease in root length in experimental side than the control side. When comparing both groups, experimental $\mathcal{P} z C$ side showed statistically significant decrease in root length compared to experimental $M O P$ side postoperatively. Conclusion: Experimental $\mathcal{P z C}$ showed statistically significant decrease in canine root length compared to experimental MOP and control side after canine retraction.

Keywords: Root resorption; microosteoperforation; peizocision; canine retraction; $C B C T$.

\section{INTRODUCTION}

Orthodontic treatment related risk factors are treatment duration, TM direction, force magnitude and technique of force applied. ${ }^{1-}$ ${ }^{3}$ The way orthodontic treatment stimulates RR is unknown. Killiany proved by evidence-based review that patients undergoing orthodontic treatment are more prone to RR. ${ }^{4}$

Apical RR is an undesirable sequelae of orthodontic therapy that may affect the result of treatment in some cases. ${ }^{5}$ Orthodontic treatment is whether continued, modified or discontinued, when RR is detected during treatment. Early detection of RR during orthodontic treatment is important for determining teeth at risk of severe resorption. ${ }^{6}$

During the last decade, many adult patients have been seeking orthodontic treatment. Prolonged treatment time can lead to increased risk of several problems such as caries, periodontal disease and RR, and that is why many adult patients refuse orthodontic treatment. $^{\text {? }}$

Keser and Dibart in 2013, ${ }^{8}$ introduced a new minimally invasive, accelerated orthodontic TM which is PzC technique. This procedure combines micro incisions and local piezoelectric surgery to achieve similar results as decortication but with minimal trauma.

Alikhani et $\mathrm{al}^{9}$ in 2013 tried MOP clinically in retraction of canine after first premolar extraction in twenty Class II div 1 patients and found that MOP increases rate of TM by 2.3 fold in experimental group compared to the control group. ${ }^{9}$

1- Lecturer of Orthodontics, Faculty of Dentistry, Alexandria University, Egypt.

2- Lecturer of Oral Medicine and Periodontology, Faculty of Dentistry, Damanhour University, Egypt. 
Hoogeveen et $\mathrm{al}^{10}$ in 2014 conducted a systemic review to evaluate effectiveness of proposed surgically facilitated orthodontic technique on orthodontic TM, including periodontal distraction, dentoalveolar distraction, corticotomy in addition to minimally invasive methods which were $\mathrm{PzC}$ and MOP and concluded that there was a low to moderate quality evidence showing that surgically facilitated orthodontics seemed to be safer for oral tissues and was characterized by a temporary phase of accelerated TM.

Many studies have documented the incidence of RR following orthodontic treatment. This was considered as a drawback of orthodontic therapy that can negatively affect the treatment outcome. Extended treatment time needed in orthodontic therapy is one of the major causes that increase the risk of RR. Due to these circumstances, many techniques were introduced in order to accelerate TM thus reducing treatment time. Hence, the aim of this study was to compare the susceptibility of external apical RR between two methods for acceleration of orthodontic TM (MOP and $\mathrm{PzC}$ assisted orthodontics).

\section{MATERIALS AND METHODS}

This study was carried out at Faculty of Dentistry, Alexandria University, Egypt. Sixteen patients, aged between 16 and 25 years, seeking orthodontic treatment and indicated for maxillary $1^{\text {st }}$ premolars extraction followed by canine retraction, equally and randomly divided into two groups. The patients were randomly allocated by a sequence generated in SPSS and the allocation was centrally concealed. The sample size was calculated using $G$ power version 3.1.9 software. The power of the study was set at 0.80 with a $95 \%$ confidence interval, and the effect size was set at 0.6. Hence, the total sample size intended for this research was 16 subjects. Principal investigator assessed the patients for eligibility and discussed the nature of the trial with patients. After obtaining approval by the ethics committee and informed consent, the allocation to experimental or control group was carried out when canine retraction was ready to be started.

In both groups, banding and bonding of the maxillary arch using fixed orthodontic appliance was performed using a self-ligating straight wire Roth appliance bracket (0.022x0.028 inch slot). This was followed by patient referral for extraction of the maxillary first premolars. The stage of leveling and alignment was then started till 0.016x0.022inch stainless steel arch-wire could be placed passively before the onset of canine retraction.

Maximum anchorage was ensured by placing mini-screws (Hubit orthodontics, Korea) bilaterally between the maxillary second premolars and first molars. The mini-screws used were $10 \mathrm{~mm}$ in length and $1.6 \mathrm{~mm}$ in diameter. Mini-screws were placed under local anaesthesia and self-drilled into the bone using a screw driver.

In group A, three MOPs were performed distal to the maxillary canine on the experimental side, while the control side received no intervention prior to the onset of canine retraction. The location of MOPs was initially identified using a periodontal probe punched through the attached gingiva. MOPs were performed using a handheld disposable device especially designed for this purpose (Propel orthodontics, Ossining, NY) under local infiltration anesthesia. The device has an adjustable length and a light signal that turns on upon achieving the desired depth during the procedure. Each perforation was $1.5 \mathrm{~mm}$ wide, and 2 to $3 \mathrm{~mm}$ deep. 
In group $\mathrm{B}$, the surgical procedure was performed under local infiltrative anaesthesia to the mesial and distal sides of the canine on the experimental side. Vertical interproximal incisions were made, $5 \mathrm{~mm}$ apical to the mesial and distal interdental papilla of the canine, on the buccal aspect using surgical blade No. 15 . Incisions were performed extending $10 \mathrm{~mm}$ in length apically through the periosteum, allowing the blade to reach the alveolar bone. A piezo surgical knife (Piezomed, tip B1) was used to create the cortical bone incisions through the gingival opening to a depth of 3 $\mathrm{mm}$ approximately. The canine on the other side served as control.

Canine retraction was then started in both groups with the same arch wire $(0.016 \times 0.022$ inch stainless steel), using nickel-titanium closed coil springs placed bilaterally, delivering a force of $150 \mathrm{gm}$ per side. The closed coil springs were stretched from the miniscrew to the canine hooks.
Before and after canine retraction, CBCT scans were taken for each patient to evaluate external apical RR. CBCT scans were acquired via the Sirona Galileos CBCT system (Sirona Dental System, Bensheim, Germany). The machine specifications were $82 \mathrm{KV}, 32 \mathrm{~mA}$, scanning time of $2.6 \mathrm{sec}$, voxel size of $0.35 \mathrm{~mm}$ amorphous silicon flat panel and $13 \mathrm{cmx} 15 \mathrm{~cm}$ FOV. The scans were saved as DICOM 3D multi-files and imported into a computer software program (Galileos implant version 1.9 SICAT, Bensheim, Germany).

The coronal, sagittal and axial plans were adjusted to intersect in the pulp chamber of the tooth in question at the level of cemento-enamel junction (CEJ). The root length was measured from the most apical point of the root to the cusp tip for the maxillary canines on both sides in both groups, along the long axis in the sagittal view. The measurements were obtained using the software tools including linear measurement tool and a digital magnification lens. (Fig 1,2)

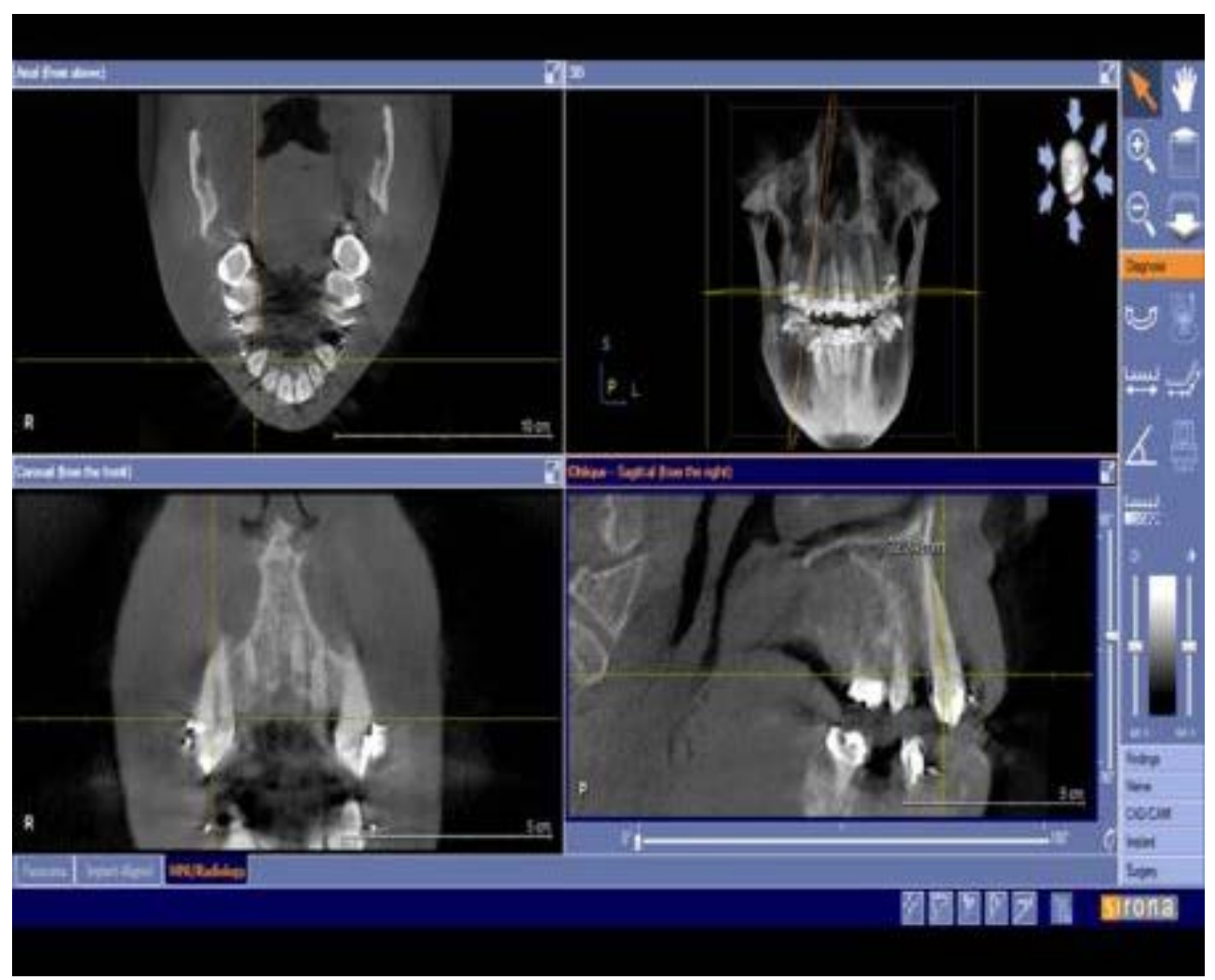




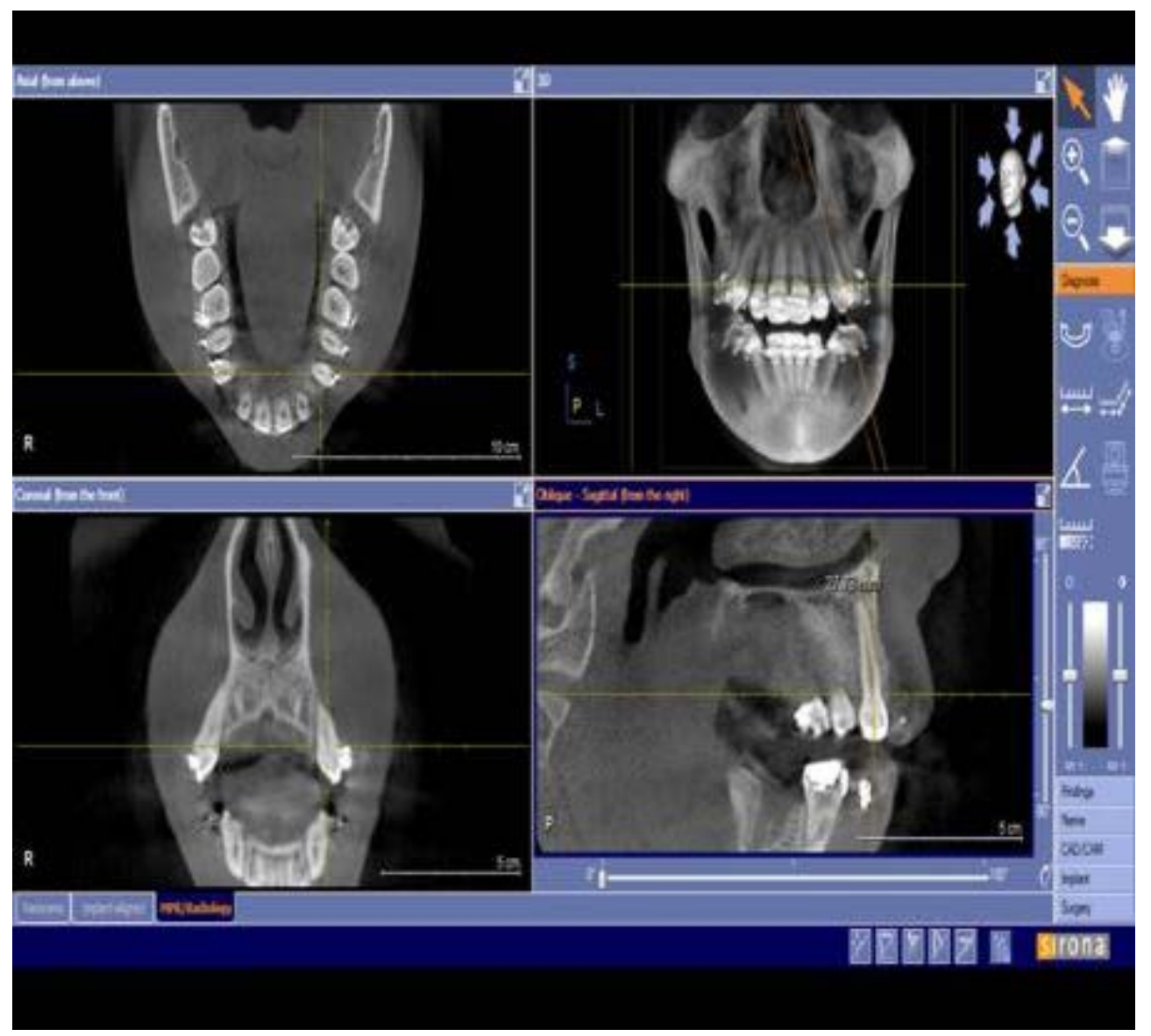

Fig 1,2: Root length measurement for the maxillary canines on both sides in both groups along the long axis in the sagittal view

\section{STATISTICAL ANALYSIS}

Analysis was done using Statistical Package for Social Sciences (SPSS version 20, Chicago, IL, USA) software. Paired t-test was used to compare between the same group (pre and post-operative), while unpaired t-test was used to compare between different two studied groups. The level of significant considered was $\mathrm{p}<0.05$. Inter class correlation (ICC) were performed for intra examiner reliability on $20 \%$ repeated measurement after 2 weeks.

\section{RESULTS}

The ICC reliability coefficient value were ranged from 0.921 to 0.945 .

Table 1shows measured values of canine root length before and after retraction in each side in MOP group. On comparing experimental side before and after retraction, there was no significant difference. Also, in the control side, there was no significant difference. On comparing between both sides after canine retraction, no significant differences were observed( $p>0.05)$.

Table 2 shows measured values of canine root length before and after retraction in each side in PzC group. On comparing experimental side before and after retraction, there was statistically significant decrease in root length $(p<0.05)$. On comparing control side before and after retraction, there was statistically significant decrease in root length $(\mathrm{p}<0.05)$. Comparing canine root length between experimental and control group after retraction showed statistically significant decrease in root length in experimental side than the control side $(\mathrm{p}<0.05)$.

Table 3 shows comparison between experimental sides in both groups, post-retraction regarding canine root length. Experimental PzC side showed statistically significant decrease in root length compared to experimental MOP side postoperatively $(\mathrm{p}<0.05)$. 
Table 1. Evaluate apical root resorption before and after in each side in Micro-osteoperforation group

\begin{tabular}{|l|c|c|c|c|}
\hline \multirow{2}{*}{ Cases } & \multicolumn{2}{|c|}{ Experimental } & \multicolumn{2}{c|}{ Control } \\
\cline { 2 - 5 } & Preoperative & Postoperative & Preoperative & Postoperative \\
\hline Range & $24.33-30.39$ & $24.19-29.29$ & $24.28-31.38$ & $24.1-29.6$ \\
Mean & 27.69 & 27.24 & 27.95 & 27.26 \\
S.D. & 2.09 & 1.76 & 2.50 & 1.94 \\
\hline p 1 & \multicolumn{2}{|c|}{0.458} & 0.106 & 0.422 \\
p 2 & \multicolumn{2}{|r|}{} & & 0.625 \\
\hline
\end{tabular}

p 1 Comparison between pre and post operative in the same group.

p 2 comparison between the two groups at the same period.

Table 2. Evaluate apical root resorption before and after in each side in Piezocision group.

\begin{tabular}{|l|c|c|c|c|}
\hline \multirow{2}{*}{ Cases } & \multicolumn{2}{|c|}{ Experimental } & \multicolumn{2}{c|}{ Control } \\
\cline { 2 - 5 } & Preoperative & Postoperative & Preoperative & Postoperative \\
\hline Range & $24.27-31.23$ & $23.7-29.6$ & $24.45-31.03$ & $23.5-29.94$ \\
Mean & 26.86 & 24.68 & 27.05 & 25.87 \\
S.D. & 2.78 & 2.00 & 2.70 & 2.56 \\
\hline P1 & \multicolumn{2}{|c|}{$0.032^{*}$} & & $0.041^{*}$ \\
\hline P2 & \multicolumn{2}{|c|}{} & & $0.033^{*}$ \\
\hline
\end{tabular}

P1 Comparison between pre and post operative in the same group.

$\mathbf{P} 2$ comparison between the two groups at the same period.

Table 3. Comparison between the two-studied group regarding apical root resorption at different subgroups and different period of measurements.

\begin{tabular}{|l|c|c|c|c|}
\hline \multirow{2}{*}{\multicolumn{1}{|c}{ Cases }} & \multicolumn{2}{c|}{ Experimental } & \multicolumn{2}{c|}{ Control } \\
\cline { 2 - 5 } Micro-osteoperforation group & Preoperative & Postoperative & Preoperative & Postoperative \\
Range & $24.33-30.39$ & $24.19-29.29$ & $24.28-31.38$ & $24.1-29.6$ \\
Mean & 27.69 & 27.24 & 27.95 & 27.26 \\
S.D. & 2.09 & 1.76 & 2.50 & 1.94 \\
\hline Piezocision group & & & & $23.5-29.94$ \\
Range & $24.27-31.23$ & $23.7-29.6$ & $24.45-31.03$ & 25.87 \\
Mean & 26.86 & 24.68 & 27.05 & 2.56 \\
\hline S.D. & 2.78 & 2.00 & 2.70 & $0.007^{*}$ \\
\hline P & 0.069 & $0.001^{*}$ & 211 & \\
\hline
\end{tabular}

$\mathbf{P}=$ comparison between the two groups at the same time. 


\section{DISCUSSION}

Orthodontic TM is influenced by mechanical force application that leads to tissue remodeling within the periodontium. One of the iatrogenic outcome of orthodontic TM is induced inflammatory RR. Alikhani et $\mathrm{al}^{11}$ in 2015 stated that shortening of orthodontic treatment time offers significant value to both orthodontist and patient. Less treatment time with fixed orthodontics reduces the risk for external apical RR.

$\mathrm{RR}$ is a $\mathrm{BD}$ phenomenon, and its extent must be measured with accuracy. Until now, although radiographic methods have limitations, they are the only tool to evaluate and measure apical RR. CBCT diagnostic ability showed high sensitivity and excellent specificity. John et $\mathrm{al}^{12}$ in 2010 concluded that CBCT is the most reliable method to measure and evaluate external apical RR than periapical radiographs which have magnification errors and lack accurate landmark identification.

Jiang et $\mathrm{al}^{13}$ in 2017 studied external apical RR using CBCT because it is an accurate imaging technique and has reliable results. There are many factors that cause RR, such as magnitude of orthodontic force applied, treatment technique and method of measuring RR. Controlling these factors was difficult in previous studies because they used data based on $2 \mathrm{D}$ radiographs that can produce deceiving errors. Using 3D CBCT to measure external apical RR eliminates errors produced when 2D radiographs are used. In this study, tooth length was used instead of root length to determine external apical RR and this eliminates the effect of different methods to define the root as it is generally accepted that crown length does not change during orthodontic treatment. ${ }^{14,15}$

Limited clinical knowledge is available on the effect of age of the patient to induce external apical RR. Present study has not investigated age and sex related differences. Jiang et al investigated multiple factors that may cause apical RR during canine retraction treatment and reported that older patients tend to have more tendency to external apical RR after canine retraction. ${ }^{13}$ It is also not clear whether the gender of the patient is a factor increasing the liability of external apical RR. However results found by Jiang et al showed that female patients tend to be more likely to experience apical $\mathrm{RR}$ but that was not statistically significant. ${ }^{13}$

Alikhani et $\mathrm{al}^{9}$ in 2013 studied the effect of MOP on rate of TM after canine retraction and found that no patient in his clinical study showed any signs of RR in routine panoramic radiograph taken as final record. However, panoramic or periapical radiographs are not accurate for measuring $\mathrm{RR}$ and recommended further studies to investigate the effect of accelerated orthodontic TM on apical RR using more accurate radiographic methods. In 2015, Alikhani et $\mathrm{al}^{11}$ studied MOPs as a minimally invasive accelerated TM technique and found that external apical $\mathrm{RR}$ is not increased following MOP treatment. One main reason for external apical RR is high stresses that produce a cell free zone when a tooth is pushed towards dense bone. In these areas, osteoclasts are recruited from the surrounding PDL and endosteal surface. The prolonged presence of osteoclasts rather than number of osteoclasts causes external apical RR. With MOP, number of osteoclasts is increased and since MOP decreases density of adjacent alveolar bone, the cell free zone is smaller and cleared faster which prevent prolonged osteoclastic activity adjacent to the tooth root. External apical RR decreases significantly in MOP treatment during TM over long distance.We found insignificant difference among experimental (MOP) and control group.

Darendeliler et al studied the effect of PzC on RR associated with orthodontic force of 150 gm using computed tomography and found that $\mathrm{PzC}$ procedure resulted in an increase in $\mathrm{RR}$ on 
all surfaces and vertical thirds when compared with control side after application of orthodontic force for 28 days. However, only total RR values reached statistical significance. It was found that $\mathrm{PzC}$ procedure resulted in $44 \%$ average increase in RR compared with control side. ${ }^{16}$ Similarly, current study also found significant difference among experimental $\mathrm{PzC}$ versus control and MOP group. Makedonas et al did not find a relation between treatment duration and $\mathrm{RR}$, where $\mathrm{PzC}$ decreased treatment duration by accelerating TM and theoretically this should decrease total $\mathrm{RR}$, but on the contrary PzC procedure resulted in more apical RRwhen compared to control side and that coincides with the results of this study. $^{17}$

\section{CONCLUSION}

1. No significant apical RR observed following the application of MOPin comparison to control side assisted orthodontics for acceleration of TM after canine retraction.

2. Significant apical RRobserved following the application of $\mathrm{PzC}$ in comparison to control side assisted orthodontics for acceleration of TM after canine retraction.

3. Significant apical RR observed following the application of $\mathrm{PzC}$ in comparison to control side and MOP assisted orthodontics for acceleration of TM after canine retraction.

\section{REFERENCES}

1. Killiany DM. Root resorption caused by orthodontic treatment: an evidence-based review of literature. Semin Orthod 1999;5:128-33.

2. Owman-Moll P, Kurol J, Lundgen D. Continuous versus interrupted continuous orthodontic force related to early tooth movement and root resorption. Angle Orthod1995;65:395-401.
3. Sameshima GT,Asgarfar KO. Assessment of root resorption and root shape:periapical vs panoramic films. Angle Orthod 2001;71:185-9.

4. Acar A, Canyurek U, Kocaaga M, Erverdi N. Continuous vs discontinuous force application and root resorption. Angle Orthod1999;69: 159-63.

5. Abuabara A. Biomechanical aspects of external root resorption in orthodontic therapy. Med Oral Patol Oral Cir Bucal 2007;12: E610-613.

6. Topkara A. External apical root resorption caused by orthodontic treatment: a review of the literature. Eur J Paediatr Dent 2011;12: 163-166.

7. Aylikco O, Sakin C. Piezocision-assisted canine distalization. J Orthod Res 2013;1:70-6.

8. Keser E, Dibart S. Sequential piezocision: A novel approach to accelerated orthodontic treatment. Am J Orthod Dentofacial Orthop 2013;144:879-89.

9. Alikhani M, Raptis M, Zoldan B, Sangsuwon C, Lee YB, Alyami B. Effect of micro-osteoperforations on the rate of tooth movement. Am J Orthod Dentofacial Orthop 2013;144(5):639-48.

10. Hoogeveen EJ, Jansma J, Ren Y. Surgically facilitated orthodontic treatment: a systematic review. Am J Orthod Dentofacial Orthop 2014;145(4):S51-S64.

11. Alikhani M, Alansari S, Sangsuwon C, Alikhani M, Chou M, Alyami B, Nervina J, Teixeira C. Micro-osteoperforations: Minimally invasive accelerated tooth movement. Semin Orthod 2015;21:162-169.

12. Sherrard JF1, Rossouw PE, Benson BW, Carrillo R, Buschang PH. Accuracy and reliability of tooth and root lengths measured on cone-beam computed tomographs. Am J Orthod Dentofacial Orthop 2010;137:S100-8.

13. Jiang F, Chen J, Kula K, Gu H, Du Y, Eckert G. Root resorptions associated with canine retraction treatment. Am J Orthod Dentofacial Orthop 2017;152:348-54.

14. Katona TR. The flaws in tooth root resorption assessment algorithms: the role of source position. Dentomaxillofac Radiol 2007;36: 311-6. 


\section{Egyptian \\ Orthodontic Journal}

15. Xia Z, Chen J, Jiang F, Li S, Viecilli RF, Liu SY. Load system of segmental T-loops for canine retraction. Am J Orthod Dentofacial Orthop 2013;144:548-56.

16. Darendeliler M, Patterson M, Dalci O, Papadopoulou A, Madukuri S, Mahon J, Petocz P, Spahr A. Effect of piezocision on root resorption associated with orthodontic force: a microcomputed tomography study. Am J Orthod Dentofacial Orthop 2017;151: 53-62.

17. Makedonas D, Lund H, Hansen K. Root resorption diagnosed with cone beam computed tomography after 6 months and at the end of orthodontic treatment with fixed appliances. Angle Orthod 2013;83:389-93. 